[Aus dem königl. Institut für Infektionskrankbeiten zu Berlin.]

(Direktor: Geh. Obermed.-Rat Prof. Dr. Gaffky.)

(Abteil.-Vorstand: Geh. Med.-Rat Prof. Dr. Wassermann.)

\title{
Über Konstitution und Spezifizität der Opsonine im normalen Serum.
}

Von

Dr. S. Hata,

vom Kaiserl. Ingtitut făr Infekttonskrankheiten in Tokio.

Nachdem vor 5 Jahren Wright und Douglas (1) ihre Opsoninlehre veröffentlicht hatten, ist die Opsoninfrage von der Wrightschen Schule und von vielen anderen Autoren nachgeprüft worden, und jetzt findet ihre Lehre eine weitverbreitete praktische Anwendung nicht nur zu diagnostischen, sondern auch zu therapeutischen Zwecken. Nach zahlreichen Beobachtungen scheint sie wenigstens bei gewissen Infektionskrankheiten, in praktischer Hinsicht mit glänzendem Erfolg gekrönt zu sein. Dagegen gehen die Versuchsresultate und damit auch die Meinungen der vielen Autoren, die sich mit dem theoretischen Ausbau der Opsoninlehre, insbesondere bezüglich der Konstitution und der Spezifizität des Opsonins, beschäftigt haben, weit auseinander.

Dieser Umstand hat mich veranlabt, auf Anregung des Hrn. Geh. Med.-Rat Prof. Wassermann einige diesbezügliche Versuche anzustellen. Von der eingehenden Besprechung der Literatur will ich absehen und auf das Sammelreferat Sauerbecks (2) hinweisen, der fast alle Arbeiten bis zum Jahre 1906 systematisch und nahezu erschöpfend zusammengefaßt hat. Die von ihm angeführte Literatur und die seither neu erschienenen Arbeiten sollen nur insoweit weiter unten bei Beschreibung eigener Versuche berücksichtigt werden, als sie zu diesen in direkter Beziehung stehen.

Zeitschr. f. Hygiene. LXI. 
Ich habe fast ausschlieBlich mit Normalopsonin des Meerschweinchens gearbeitet. Das Meerschweinchenserum oder dessen Komponenten wurden stets sowohl auf opsonische Kraft als auch auf hämolytische Wirksamkeit untersucht, um diese beiden Fähigkeiten einem Vergleiche unterziehen zu können. Die ganze Arbeit wird zweckmäBig in drei Kapiteln: Beziehung des Opsonins zum Komplement, Konstitution des Opsonins und Spezifizität desselben, abgehandelt werden.

\section{Beziehung des Opsonins zum Komplement.}

Wright und Douglas (1) fanden im auf $60^{\circ}$ erhitzten Normalserum keine opsonische Wirkung mehr. Ein mit erhitztem Serum verdünntes frisches Serum zeigte keine stärkere opsonische Kraft als ein mit physiologiseher Lösung verdünntes, frisches Serum. Also war das einmal inaktivierte Serum nicht mehr reaktivierbar. Auch Bulloch und Atkin (3) kamen zu dem gleichen Resultate, daB die Erwärmung das Opsonin nicht nur zu einer inaktiven Modifikation umändere, sondern imstande sei, es ganz zu vernichten. Daraus schlossen sie, daB das Opsonin ein einfacher Körper und nicht identisch mit irgend einem der bisher bekannten Antikörper sei. Bächer (4) inaktivierte ein Normalopsonin durch $1 / 2$ stündige Erwärmung bei $56^{\circ}$. So inaktiviertes Serum soll keine hemmende Faktoren auf die opsonische Kraft des frischen Serums gehabt haben, also ein völlig indifferentes Medium sein. Nach diesen Arbeiten scheint das Opsonin ein ganz einfacher thermolabiler Körper zu sein und eine dem Komplement sehr ähnliche Natur zu haben. Muir und Martin (5) haben mit drei Arten Ambozeptor + Rezeptor-Kombinationen ein frisches Serum behandelt. Nachdem das Serum durch diese Behandlung seines Komplements beraubt worden war, hatte es keine hämolytische, bakteriolytische und opsonische Kraft mehr in sich. Aus diesen Ergebnissen ihrer Versuche hatten die Autoren sich für berechtigt gehalten, auf die Identität des Opsonins und Komplements zu schließen:

Demgegenüber fand Dean (6) sowohl im Normal- wie auch im Immunserum zwei Opsonine, ein thermolabiles, ein thermostabiles, und zwar in jenem thermolabiles, in diesem thermostabiles in überwiegender Menge. Nach ihm soll jedes dieser beiden Opsonine für sich allein wirksam sein kōnnen. Cowie und Chapin (7) inaktivierten normales Meerschweinchenserum dưrch Erwärmung auf $60^{\circ}$ und konnten das erbitzte, für sich allein unwirksame Serum durch Zusatz einer geringen Menge frischen Serums, die für sich allein nahezu keine Phagozytose mebr hervorrief, wieder reaktivieren. Daher schlossen sie, das Opsonin sei wie andere Immunkörper aus zwei Komponenten, d. h. Ambozeptor und Komplement 
zusammengesetzt. Hektoen und Rüdiger (8), sowie Neumann (9) vertreten noch eine andere Meinung: daB nämlich das Opsonin weder mit Komplement noch mit Ambozeptor identisch sei. Hektoen und $R$ ủ diger wollen das Opsonin vielmehr mit dem Toxin verglichen wissen.

Zur Erforschung der Konstitution des Opsonins waren bisher nur die Inaktivierung durch Hitze und die Absorption durch Bakterien in Anwendung gebracht worden.

Im letzten Jahre hat Ferrata (10) entdeckt, daB bei der Dialyse des Meerschweinchenserums das hämolytische Komplement in zwei Komponenten zerfällt, von denen die eine in dem bei der Dialyse ausfallenden und danach abzentrifugierten Globulinniederschlag, die andere in der überstehenden Flüssigkeit enthalten ist. Jede dieser Komponenten ist an und für sich unwirksam, ihre Vereinigung in salzhaltiger Lösung führt zur Wiederherstellung des hämolytisch wirksamen Komplements. Brand (11) konnte diese Entdeckung Ferratas bestätigen und in weiterem Verfolg dieser Tatsachen fand er seinerseits, daB von den ambozeptorbeladenen Blutkörperchen nur die im Sediment enthaltene Komponente gebunden wird, die Komponente des Abgusses dagegen in keiner direkten Beziehung zu dem Komplex, Ambozeptor + Rezeptor, steht. Auf Grund dieser Anschauung wurde die Sedimentkomponente „Mittelstück", die AbguB. komponente „Endstück“ benannt. Dieses merkwürdige Phänomen wurde darauf auch von Hecker (12) als vollauf richtig bestätigt.

Mit dieser neuen Methode unternahm ich es nun das Opsonin zu analysieren und $\mathrm{zu}$ untersuchen, $\mathrm{ob}$ das Normalopsonin des Meerschweinchenserums ebenso wie das hämolytische Komplement durch Dialyse in zwei Komponenten zerfällt. Zu diesem Zwecke wurden zuerst die Versuche der genannten drei Autoren bezüglich der hämolytischen Wirksamkeit des Gesamtdialysats und seiner beiden Komponenten einer Nachprüfung unterzogen, gleichzeitig aber auch stets in einem Parallelversuch die opsonische Kraft dieser Substanzen vergleichend festgestellt. Hier soll zunächst nur von den hämolytischen Versuchen die Rede sein.

\section{a) Hämolyse mit dialysierten Meerschweinchenseris als Komplement.}

Bei diesen Versuchen, wurde je $1^{\mathrm{cem}}$ einer 5 prozentigen Aufschwemmung von dreimal gewaschenen Hammelblutkörperchen in physiologischer Kochsalzlösung gebraucht. Als Ambozeptor diente das inaktivierte Serum eines mit Hammelblut vorbehandelten Kaninchens, von welchem, wie durch einen $\nabla$ orversuch festgestellt worden war, $0.005 \mathrm{~cm}$ genügten, um 1 ecm 5 prozentiger Blutaufschwemmung unter Mitwirkung von $0.05^{\mathrm{ecm}}$ 
Meerschweinchenserum als Komplement komplett aufzulösen. Bei dem Hauptrersuche wurden zu je $1 \mathrm{~cm}$ Hammelblutaufschwemmung $0.05 \mathrm{~cm}$ also die 10 fach lösende Dose des Ambozeptors zugesetzt. Diese Mischung wurde 30 Minuten lang bei $\mathbf{3 7}^{\circ}$ im Brütschrank gehalten, dann zentrifugiert, gewaschen und wieder auf 5 Prozent aufgeschwemmt. So mit Ambozeptor beladenes Blut bezeichne ich mit „Amb.-Bl.“. Als Komplement wurde immer ganz frisches Meerschweinchenserum benutzt. Ein kleiner Teil des frischen Meerschweinchenserums wurde, um ihn den gleichen äußeren Bedingungen (Temperatur, Belichtung), wie den zu dialysierenden Teil auszusetzen, während der Dialyse in einem kleinen, in das Dialysierungswasser eingetauchten Reagensgläschen zurūckbehaiten. Dieses nicht dialysierte Originalserum wurde zu Kontrollversuchen benutzt, die von den obengenannten Autoren nicht angestellt worden waren. Derartige Kontrollversuche sind von großer Wichtigkeit, weil man dadurch bemessen kann, ob und wie stark die hämolytische sowie die opsonische Wirksamkeit des Serums durch die Dialyse allein eine Einbuße erleide. Der Hauptteil ( 3 bis 4 cem) des Serums wurde in einem Fischblasenkondom gegen verschiedene der unten näher zu beschreibenden Dialysierungsmedien 24 Stunden lang dialysiert. Dabei war das Volumen des Serums um 70 bis 100 Prozent gestiegen. Von dem erhaltenen Gesamtdialysat wurde ein kleiner Teil zur Prüfung sowohl auf hämolytische als auch auf opsonische Wirksamkeit entnommen. Der übrige Teil wurde in ein salzfrei gewaschenes und getrocknetes Zentrifugiergläschen gebracht und zentrifugiert. Die durch Zentrifugierung klar gewordene Flüssigkeit wurde in ein anderes Zentrifugiergläschen abgegossen und nochmals zentrifugiert, dann durch ein Filtrierpapier, Schleicher und Schüll extra hart Nr.602, filtriert („Filtrat"). Das durch die erstmalige Zentrifugierung ausgeschleuderte Sediment wurde mit demselben Wasser, das als Dialysierungsmedium gedient hatte, zweimal gewaschen und nach jedesmaliger Waschung zentrifugiert. Die Zentrifugierung muB mit einer Geschwindigkeit von 2500 Touren pro Minute wenigstens 30 Minuten lang ausgeführt werden, weil sonst die ganz feinen, schwer fällbaren Eiweißpartikelchen in der Flüssigkeit zurückbleiben und verloren gehen. Zum Waschen des Sedimentes wurde von den Autoren immer destilliertes Wasser gebraucht, was meiner Ansicht nach nicht richtig ist. Das von ihnen zur Dialysierung benutzte Leitungswasser ist nicht salzfrei. So ist es möglich, daB der im Sediment zurückbleibende noch in Leitungswasser lösliche, in destilliertem Wasser aber unlösliche Bestandteil durch salzfreies destilliertes Wasser ausgefällt wird und zum Sediment übergeht. Das gut gewaschene Sediment wurde mit physiologischer Kochsalzlösung aufgelöst und mit derselben auf das Ausgangsvolumen des Dialysates aufgefüllt („Sediment- 
lösung"). Durch Zusatz von physiologischer Kochsalzlösung wurde das Originalserum, das Gesamtdialysat, das Filtrat und die Sedimentlösung zu gleichem Volumenverhältnisse, d. h. auf ein gewisses Multiplum (gewöhnlich 3 fach) des Originalserums aufgefüllt. Dies soll für ein Serum, dessen Volumen durch. Dialyse um 70 Prozent gestiegen war, im folgenden Beispiel erläutert werden.

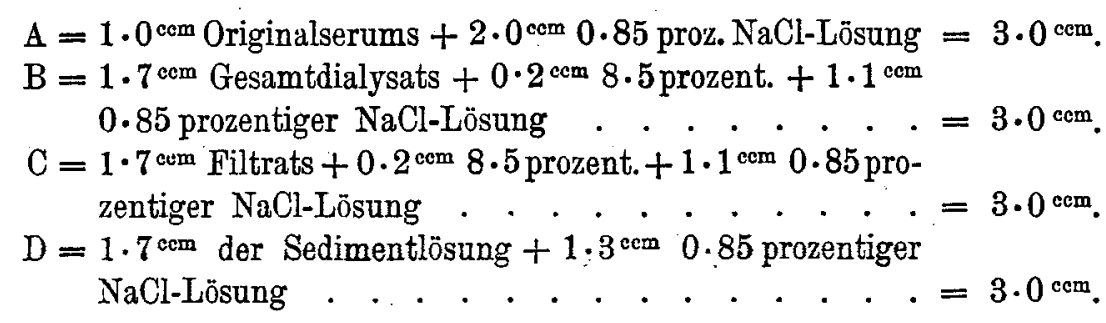

Wie man leicht ersehen kann, entspricht 1 Volumen jeder dieser Verdünnungen $1 / 3$ Volumen des Augangsserums und alle sind von ungefähr gleicher Salzkonzentration. Bei hämolytischen Versuchen wurden steigende Mengen von A, B, C, D und C + D in eine Reihe von Reagensröhrehen verteilt, mit physiologischer Lösung auf $1 \mathrm{~cm}$ aufgefüllt und je $1 \mathrm{ccm}$ Amb.-Bl. zugesetzt. Diese Blutgemische wurden gut geschüttelt; dann 1 Stunde lang bei $\mathbf{3 7}{ }^{\circ}$ belassen, darauf wiẹder geschüttelt und 24 Stunden lang im Eisschrank aufbewahrt.

Zuerst dialysierte ich das Serum gegen flieBendes Leitungswasser und verfuhr weiter wie oben beschrieben. Die folgenden Tabellen sollen die Resultate dieser Versuche ersichtlich machen.

Tabelle I.

Hämolyse mit 24 Stunden lang gegen Leitungswasser dialysiertem Meerschweinchenserum als Komplement.

\begin{tabular}{|c|c|c|c|c|c|c|}
\hline \multicolumn{2}{|c|}{$\begin{array}{l}\text { Menge des Serums bzw. } \\
\text { des Dialysates oder dessen } \\
\text { Komponenten in ccm }\end{array}$} & A & B & C & $\mathrm{D}$ & $\mathrm{C}+\mathrm{D}^{\mathrm{I}}$ \\
\hline 0.3 & a : & komplett & komplett & schwach & - & komplett \\
\hline $0 \cdot 15$ & 可可是 & & & Spur & - & $"$ \\
\hline 0.06 & 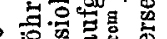 & fast kompl & fast kompl. & 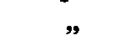 & - & fast kompl. \\
\hline 0.03 & 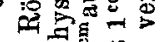 & stark & stark & Spürchen & - & stark \\
\hline 0.015 & $\stackrel{20}{=}$ & schwach & schwach & - & - & schwach \\
\hline 0.006 & 范范 & Spur & Spur & - & - & Spur \\
\hline 0.003 & & Spürchen & Spürchen & - & - & - \\
\hline
\end{tabular}

1 In der Rubrik C + D kam sowohl von C wie von D die in der ersten Rubrik angeführte Menge zur Verwendung, also zum Beispiel $0.3 C+0.3 D=0.6$ Gesamtmenge. 
Tabelle II. Hämolyse mit 24 Stunden lang gegen Leitungswasser dialysiertem Meerschweinchenserum als Komplement.

\begin{tabular}{|c|c|c|c|c|c|}
\hline $\begin{array}{l}\text { Menge des Serums bzw. } \\
\text { des Dialysates oder dessen } \\
\text { Komponenten in ccm }\end{array}$ & A & B & C & $\mathrm{D}$ & $C+D$ \\
\hline 0.3 & komplett & komplett & stark & - & komplett \\
\hline 0.15 & & & schwach & - & fast komp \\
\hline 0.06 & fast kompl & fast kompl. & Spur & - & stark \\
\hline 0.03 & stark & stark & "ג & - & , \\
\hline 0.015 & , & schwach & Spürchen & - & schwach \\
\hline 0.006 & $\operatorname{sch} w a \operatorname{ch}$ & , & - & - & Spur \\
\hline 0.003 & Spar & Spur & - & - & - \\
\hline
\end{tabular}

Ta belle III. Hämolyse mit 48 Stunden lang gegen Leitungswasser dialysiertem Meerschweinchenserum als Komplement.

\begin{tabular}{|c|c|c|c|c|c|}
\hline $\begin{array}{l}\text { Menge des Serums bzw. } \\
\text { des Dialysates oder dessen } \\
\text { Komponenten in ccm }\end{array}$ & A & B & $\mathrm{C}$ & D & $C+D$ \\
\hline 0.3 & komplett & komplett & schwach & - & komplett \\
\hline 0.15 & & ", & Spur & - & fast kompl. \\
\hline 0.06 & fast kompl. & fast kompl. & " & - & stark \\
\hline 0.03 & stark & stark & "פ & - & schwach \\
\hline 0.015 & schwach & schwach & - & - & Spur \\
\hline 0.006 & Spar & Spürchen & - & - & - \\
\hline 0.003 & - & - & - & - & - \\
\hline
\end{tabular}

Wie diese Versuchsresultate zeigen, wurde eine ziemlich deutliche Hämolyse durch Filtrat allein hervorgerufen. Mehrmals wiederholte Untersuchungen gaben stets gleiche Resultate so lange, als ich zur Dialyse das Berliner Leitungswasser, wie es an das hiesige Institut geliefert wird, benutzte. Mit Berliner Leitungswasser soll es aber Ferrata (10) gelungen sein, das Serum in ganz wirkungslose Komponenten zu spalten. Brand (12) brauchte Frankfurter Leitungswasser und sàgt: „Meist übt der AbgaB bereits an und für sich eine mehr oder weniger beträchtliche komplettierende Wirkung aus, zuweilen auch das Sediment" und ,jedenfalls gelang es im weiteren Verlauf bei Verwendung frisch gewonnenen Meerschweinchenserums, die beiden Komponenten ziemlich regelmäßig in fast oder vollständig inaktiver Form zu erhalten." Wie jedoch aus seiner Tabelle hervorgeht, erzeugte das Filtrat auch bei seinen Versuchen eine wenn auch nur spurweise Hämolyse. Nach ihm benutzte ich immer ganz frisches Serum, trotzdem aber lieB das Filtrat stets schwache Hämolyse ${ }^{1}$ erkennen, dagegen niemals der Rückstand.

'Anmerkang bei der Korrektar: Kürzlich hat auch Neufeld (13) berichtet, daB es ihm nicht gelungen sei, mit Berliner Leitungswasser Serum in seine unwirksamen Komponenten zu zerlegen. 
In weiteren Versuchen dialysierte ich das Serum gegen destilliertes Wasser und kam dabei zu folgenden Resultaten.

Tabelle IV.

Hämolyse mit 24 Stunden lang gegen destilliertes Wasser dialysiertem Serum als Komplement.

\begin{tabular}{|c|c|c|c|c|c|}
\hline $\begin{array}{l}\text { Menge des Serums bzw. } \\
\text { des Dialysates oder dessen } \\
\text { Komponenten in ccm }\end{array}$ & A & B & C & D & $\mathrm{C}+\mathrm{D}$ \\
\hline $0 \cdot 3$ & komplett & komplett & - & komplett & komplett \\
\hline 0.15 & & & - & fast kompl. & \\
\hline 0.06 & fast kompl. & fast kompl. & - & stark & fast kompl. \\
\hline 0.03 & stark & stark & - & schwach & stark \\
\hline 0.015 & schwach & schwach & - & & schwach \\
\hline 0.006 & Spur & Spur & - & Spur & $"$ \\
\hline 0.003 & Spürchen & - & - & - & Spar \\
\hline
\end{tabular}

Tabelle V.

Hämolyse mit 48 Stunden lang gegen destilliertes Wasser dialysiertem Serum als Komplement.

\begin{tabular}{|c|c|c|c|c|c|}
\hline $\begin{array}{l}\text { Menge des Serums bzw. } \\
\text { des Dialysates oder dessen } \\
\text { Komponenten in ccm }\end{array}$ & A & B & C & D & $\mathrm{C}+\mathrm{D}$ \\
\hline 0.3 & komplett & komplett & - & komplett & komplett \\
\hline 0.15 & $"$ & fast kompl. & - & fast kompl. & fast kompl. \\
\hline 0.06 & fast kompl & stark & - & stark & stark \\
\hline 0.03 & stark & $n$ & - & schwach & $\eta$ \\
\hline 0.015 & schwach & schwach & - & " & schwach \\
\hline 0.006 & Spur & Spürchen & - & - & Spur \\
\hline 0.003 & - & - & - & - & - \\
\hline
\end{tabular}

Hier gehen fast alle wirksamen Serumbestandteile ins Sediment ûber. Es ist somit klar, daß bei der Dialyse der Salzgehalt des Wassers eine wichtige Rolle spielt, indem das sogenannte Endstück in salzfreiem Wasser nicht löslich ist, und die richtige Trennung der beiden. Komponenten erst bei geeigneter Salzkonzentration des Wassers zu erwarten steht. Um letztere festzustellen, mischte ich in bestimmten Mengenverhältnissen Leitungs- und destilliertes Wasser in einem Glaszylinder von $1200^{\mathrm{ccm}}$ Inhalt. In dem Wassergemisch wurde $3^{\mathrm{ccm}}$ des frischen Serums unter ca. 6 maliger Erneuerung des Gemisches 24 Stunden lang dialysiert. Erst nach vielfachen Versuchen mit verschiedenen Wassergemischen gelang es mir, ein Optimum der Salzkonzentration zu finden, wie die folgende Tabelle es ersichtlich macht. 
Tabelle VI.

\begin{tabular}{|c|c|c|c|}
\hline \multirow{2}{*}{ Versuchs-Nr. } & $\begin{array}{l}\text { Als Dialysierungsmedium benutztes } \\
\text { Wassergemisch aus }\end{array}$ & \multicolumn{2}{|c|}{$\begin{array}{c}\text { Hämolyse } \\
\text { des } 1 \text { ccm Amb.-Bl. durch }\end{array}$} \\
\hline & Leitangswasser + destill. Wasser & $\begin{array}{l}\text { Filtrat } \\
0 \cdot 3^{\text {cam }}\end{array}$ & $\begin{array}{c}\text { Sediment } \\
0 \cdot 3_{\text {cond }}\end{array}$ \\
\hline 1 & $400 \mathrm{ccm}+800 \mathrm{com}$ & - & stark \\
\hline 2 & $800,+400$, & schwach & - \\
\hline 3 & $800 "+400$, & Spur & - \\
\hline 4 & $800 "+400 \%$ & schwach & 一 \\
\hline 5 & $700 \eta+500$, & Spur & - \\
\hline 6 & $700 "+500 \eta$ & $\eta$ & - \\
\hline 7 & $650 "+550 "$ & $\begin{array}{l}\text { letztes } \\
\text { Spürchen }\end{array}$ & $\begin{array}{l}\text { letztes } \\
\text { Spürchen }\end{array}$ \\
\hline 8 & $650 "+550$, & , & - \\
\hline 9 & $650 "+550 "$ & , & - \\
\hline 10 & $650 n+550 n$ & - & 一 \\
\hline
\end{tabular}

Danach also stellt ein Wassergemisch aus $650^{\mathrm{ccm}}$ Leitungswasser und 550 crm destilliertem Wasser ungefähr das Optimum der Salzkonzentration dar. Kleine Differenzen, wie sie die vier letzten Versuche zeigen, hängen von Faktoren (wie der-Temperatur des Wassers, der Dichtigkeit des Kondoms usw.) ab, welche auf die Osmose einen gewissen Einflub ausüben, aber bei den einzelnen Versuchen nicht konstant sind. Von diesen Versuchen sollen nur zwei Beispiele (Nr. 9 und Nr. 10) in den folgenden Tabellen VII und VIII ausführlich wiedergegeben werden.

\section{Tabelle VII.}

Hämolyse mit 24 Stunden lang gegen das optimale Wassergemisch dialysiertem Serum als Komplement.

\begin{tabular}{|c|c|c|c|c|c|}
\hline $\begin{array}{l}\text { Menge des Serums bzw. } \\
\text { des Dialysates oder dessen } \\
\text { Komponenten in ccm }\end{array}$ & $\mathbf{A}$ & B & $\mathrm{C}$ & $\mathrm{D}$ & $C+D$ \\
\hline 0.3 & komplett & komplett & Spürchen & - & komplett \\
\hline $0 \cdot 15$ & & fast kompl. & - & - & fast kom \\
\hline 0.06 & fast kompl. & stark & - & - & stark \\
\hline 0.03 & stark & $"$ & - & - & $"$ \\
\hline 0.01 , & schwach & schwach & - & - & schwach \\
\hline 0.006 & $"$ & Spur & - & - & Spur \\
\hline 0.003 & Spur & - & - & - & Spürchen \\
\hline
\end{tabular}

1 com Amb.-Bl. $+0.2^{\mathrm{com}} \mathrm{C}$ wurde $30^{\prime}$ bei $37^{\circ}$ gehalten, zentrifugiert, gewaschen $+1 \mathrm{com}$ physiolog. Lösung $+0.2^{\circ \mathrm{em} D}-$ $1^{\mathrm{ccm}}$ Amb.-Bl. $+0.2^{\mathrm{ccm}} \mathrm{D}$ wurde $30^{\prime}$ bei $37^{\circ}$ gehalten, zentrifugiert, gewaschen

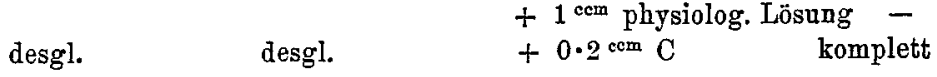


Tabelle VIII.

Hämolyse mit 24 Stunden lang gegen das optimale Wassergemisch dialysiertem Serum als Komplement.

\begin{tabular}{|c|c|c|c|c|c|}
\hline $\begin{array}{l}\text { Menge des Serums bzw. } \\
\text { des Dialysates oder dessen } \\
\text { Komponenten in cem }\end{array}$ & A & B & $\mathrm{C}$ & $\mathrm{D}$ & $C+D$ \\
\hline 0.3 & komplett & komplett & - & - & komplett \\
\hline 0.15 & 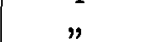 & fast kompl. & - & - & fast kompl. \\
\hline 0.06 & fast kompl. & stark & - & - & stark \\
\hline 0.03 & stark & $"$ & - & - & schwach \\
\hline 0.015 & schwach & schwach & - & - & $n$ \\
\hline 0.006 & Spar & Spur & - & - & Spur \\
\hline 0.003 & $"$ & - & - & - & - \\
\hline
\end{tabular}

1.0 ${ }^{\mathrm{cm}} \mathrm{Amb} . \mathrm{Bl} .+0.2 \mathrm{~cm} \mathrm{C}$ wurde $30^{\prime}$ bei $37^{\circ}$ gehalten, zentrifugiert, gewaschen desgl. $+1 \mathrm{~cm}$ physiolog. Lösung -

$1 \cdot 0$ com Amb.-B

$$
+0.2^{\mathrm{cm}} \mathrm{D}
$$

desgl.

desgl. +1 cem physiolog. Lösung $+0.2 \operatorname{com} \mathrm{C}$ komplett

Durch diese Versuche ist gleichzeitig bewiesen, daß die Sedimentkomponente sich direkt mit dem Ambozeptor-Blutkörperchen verbindet, während die Filtratkomponente keine direkte Beziehung zu diesem Komplex hat und erst durch Vermittelung jener auf diesen einwirkt. Diese Filtratkomponente, das sogenannte Endstück, ist aber in reinem Wasser unlöslich. Wenn daher das Filtrat noch 24 Stunden lang gegen destilliertes Wasser dialysiert wird, dann fällt das Endstüek quantitativ aus und das dabei erhaltene zweite Filtrat hat überhaupt keine hämolytische Kraft mehr.

Tabelle IX.

Meerschweinchenserum wird 24 Stunden lang gegen das optimale Wassergemisch, das Filtrat darauf weiter 24 Stunden gegen destilliertes Wasser dialysiert. Das nach dieser zweiten Dialyse erhaltene Filtrat wird mit $\mathrm{C}^{\prime}$, das Sediment mit $\mathrm{C}^{\prime \prime}$ bezeichnet.

\begin{tabular}{c|c|c|c|c|c|c|c|c}
\hline $\begin{array}{c}\text { Menge des Serums } \\
\text { bzw. des jeden } \\
\text { Komponenten in com }\end{array}$ & A & C $^{\prime}$ & $C^{\prime \prime}$ & $D$ & $C^{\prime}+D$ & $C^{\prime \prime}+D$ & $C^{\prime}+C^{\prime \prime}$ & $C^{\prime}+C^{\prime \prime}+D$ \\
\hline $\begin{array}{l}0.3 \\
0.15 \\
0.06\end{array}$ & fomplett & - & Spur & - & - & komplett & Spur & komplett \\
fast kompl. & - & - & - & - & stark & - & $\begin{array}{c}\text { fast kompl. } \\
\text { stark }\end{array}$
\end{tabular}

Also wirkt $C^{\prime}+C^{\prime \prime}$ ganz gleich wie $C^{\prime \prime}$ und $C^{\prime}+C^{\prime \prime}+D$ ganz gleich wie $C^{\prime \prime}+D$, d. h. C', das zweite Filtrat, ist gänzlich wirkungslos. 
Wie schon auseinandergesetzt, stellt ein Wassergemisch aus $650 \mathrm{~cm}$ Leitungswasser und $550 \mathrm{~cm}$ destilliertes Wasser das für unseren Zweek optimale Dialysierungsmedium dar. Wenn aber der Salzgehalt unseres Leitungswassers nicht bekannt ist, so kann man die für unsere Zwecke notwendige absolute Salzkonzentration nicht feststellen. Ich führte deshalb eine Analyse des Berliner Leitungswassers aus, nach welcher in 1 Liter folgende Mengen Rüekstand und Asche enthalten sind:

$\begin{array}{llll} & & \begin{array}{c}\text { Versuch I } \\ \text { Rüekstand nach Abdampfen . . . . } 0.2669 \mathrm{grm}\end{array} & \begin{array}{c}\text { Versuch II } \\ 0.2696 \mathrm{grm}^{\mathrm{m}}\end{array} \\ \text { Asche . . . . . . . . . . . } 0.1610, & 0.1614,\end{array}$

Aus dieser Analyse geht hervor, daB der Salzgehalt des Wassers ziemlich groB ist. Mit diesen Zahlen läßt sich jedoch der osmotische Druck des Wassers nicht berechnen, da dieses keine einfache Salzlösung ist. Das Wasser enthält außer Chlornatrium auch Calcium- und Eisensalz durch Kohlensäure gelöst und daneben organische Substanzen. Aber selbst, wenn wir auch diese Substanzen quantitativ und qualitativ bestimmen würden, so könnten wir damit doch noch nicht den osmotischen Druck ermitteln. Ich versuchte daher eine Orientierung über den osmotischen Druck des Wassers zu gewinnen, indem ich mit Hilfe des Beckmannschen Apparates die Gefrierpunktserniedrigung des Wassers bestimmte und diese einem Vergleich mit der der reinen Kochsalzlösung unterzog. Dieser Apparat lieferte mir durchschnittlich folgende Zahlen.

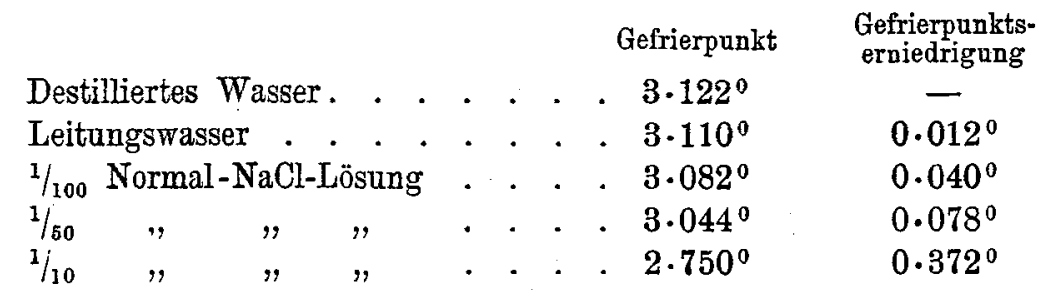

Da die Erniedrigung des Leitungswassers zu gering war, suchte ich durch Eindampfen seinen Salzgehalt soweit zu erhöhen, daB es ungefähr eine mit der Gefrierpunktserniedrigung der $1 / 100$ Normal NaCl-Lösung vergleichbare Erniedrigung liefere. Dies war jedoch nicht möglich, weil beim Eindampfen des Wássers dureh die Austreibung der Kohlensäure das Calciumsalz zur Ausfällung kam. Ich habe mich deshalb mit den obenangeführten Zahlen zufriedengegeben und nach ihnen den Salzgehalt des Wassers mit dem einer Normalkochsalzlösung in Vergleich gesetzt. Wie es scheint, entspricht die Gefrierpunktserniedrigung des Leitungswassers ungefähr der einer $1 / 300$ bis $1 / 400$ Normal-NaCl-Lösung. Danach 
rechnete ich den Salzgehalt des obengenannten optimalen Wassergemisches auf reine Kochsalzlösung um, wie folgt:

$$
\begin{aligned}
\frac{1}{300} \times \frac{650}{650+550}=\text { ungefähr } \frac{1}{554} \\
\text { oder: } \frac{1}{400} \times \frac{650}{650+550}=\text { ungefähr } \frac{1}{740} .
\end{aligned}
$$

Wenn diese Bestimmung richtig ist, so kann man wohl das optimale Wassergemisch durch eine $1 / 554$ bis $1 / 740$ Normal-NaCl-Lösung ersetzen, und dürfte das Serum bei Dialysierung gegen eine derartige Lösung sicher in zwei unwirksame Komponenten zerfallen. Natürlich gibt eine solche Berechnung nur eine Orientierung. Ich stellte mir verschiedene Normallösungen ( Probedialysen aus, wie dies vorher mit dem Wassergemisch geschehen war.

Tabelle X.

Hämolyse mit 24 Stunden lang gegen verschiedene Normal-NaCl-Lösungen

\begin{tabular}{|c|c|c|c|c|}
\hline \multirow{2}{*}{$\begin{array}{l}\text { Versuchs- } \\
\text { nummer }\end{array}$} & \multirow{2}{*}{\multicolumn{2}{|c|}{$\begin{array}{c}\text { Als Dialysierungswasser } \\
\text { warde benutzt }\end{array}$}} & \multicolumn{2}{|c|}{$\begin{array}{c}\text { Hämolyse des } 1 \text { ccm Amb.-Bl. } \\
\text { durch }\end{array}$} \\
\hline & & & Filtrat $0.3^{\mathrm{cem}}$ & Sediment $0.3 \mathrm{ccm}$ \\
\hline 1 & $1 / 800$ & Normal-NaCl-Lösung. & - & schwach \\
\hline 2 & $1 / 700$ & desgl. & - & " \\
\hline 3 & $1 / 400$ & , & schwach & - \\
\hline 4 & $1 / 600$ & , & Spürchen & Spur \\
\hline 5 & $1 / 600$ & , & - & " \\
\hline 6 & $1 / 550$ & , & Spürchen & - \\
\hline 7 & $1 / 550$ & ", & - & Spürchen \\
\hline 8 & $1 / 550$ & " & letztes__Spürchen & letztes Spürchen \\
\hline
\end{tabular}
dialysierten Seris als Komplement.

Wie es bei den Proben mit Wassergemisch der Fall war, so waren auch hier die dureh den EinfluB der obengenannten l'aktoren bedingten kleinen Differenzen zwischen den letzten drei Versuchen zu beobachten. Aber wir glauben uns nach den hier wiedergegebenen Resultaten zu dem Schlusse berechtigt, mit der obenangeführten Berechnung das Richtige getroffen zu haben. $1 / 500$ bis $1 / 600$ Normal-NaCl-Lösung stellt somit die für unseren Zweck optimale Salzkonzentration dar. Aus diesen Versuchen soll nur ein Beispiel in der folgenden Tabelle ausführlich wiedergegeben werden. 
Tabelle XI (Versuch Nr. 6).

Hämolyse mit 24 Stunden lang gegen eine $1 / 550$ Normal-NaCl-Lösung dialysiertem Serum als Komplement.

\begin{tabular}{|c|c|c|c|c|c|}
\hline $\begin{array}{l}\text { Menge des Serums bzw. } \\
\text { des Dialysates oder dessen } \\
\text { Komponenten in ccm }\end{array}$ & A & B & $\mathrm{C}$ & $\mathrm{D}$ & $\mathbf{C}+\mathbf{D}$ \\
\hline 0.3 & komplett & komplett & Spürchen & - & komplett \\
\hline $0 \cdot 15$ & , & fast kompl. & - & - & fast kompl. \\
\hline 0.06 & fast kompl. & stark & - & - & stark \\
\hline 0.03 & stark & " & - & - & " \\
\hline 0.015 & schwach & schwach & - & - & schwach \\
\hline 0.006 & Spar & Spar & - & - & Spur \\
\hline 0.003 & Spürchen & - & - & - & - \\
\hline
\end{tabular}

$1.0^{\mathrm{ccm}}$ Amb.-Bl. $+0.2^{\mathrm{om}} \mathrm{C}$ wurde $30^{\circ}$ bei $37^{\circ}$ gehalten, zentrifugiert, gewaschen $\begin{array}{lll} & +1.0 \mathrm{com} \text { physiolog. Lösung - } \\ \text { desgl. desgl. } & +0.2, \mathrm{D}\end{array}$

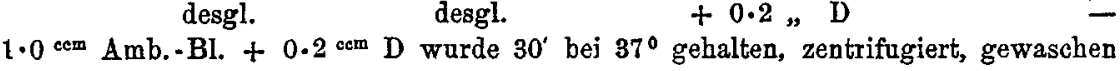
$\begin{array}{lll} & +1.0 \mathrm{~cm} & \text { physiolog. Lösung - } \\ \text { desgl. } & +0.2, \mathrm{C} & \text { komplett }\end{array}$

Werfen wir einen Rückblick auf die Resultate der bisher angeführten Versuche, so ergibt sich, daB ein Normal-Meerschweinchenserum durch Dialyse gegen Wasser von bestimmter Salzkonzentration in zwei an und für sich unwirksame Komponenten zerlegt wird, durch deren Vereinigung das Komplement in seiner ursprünglichen Wirksamkeit wiederhergestellt wird. Während sich die eine Komponente als Zwischenstück im Sinne Brands direkt mit $A \mathrm{mb}$.-Bl. verbindet, wirkt die andere als Endstüek erst durch Vermittelung des Zwischenstücks auf den Komplex ein. Damit ist die Angabe von Ferrata, Brand und Hecker tatsächlich vollkommen bestätigt worden. Von der Beantwortung der Frage, ob die beiden Komponente von absolut verschiedener Natur oder vielmehr nur von gradueller Differenz sind, will ich mich vorläufig enthalten und gehe nunmehr zur Beschreibung der opsonischen Versuche, welche mit den hämolytischen Versuchen parallel durchgeführt wurden, über.

b) Opsonische Versuche mit dialysierten Meerschweinchenseris.

Als Opsonine dienten die oben genau beschriebenen Substanzen $A$, B, C, D und C + D. An Bakterien benutzte ich fast ausschlieBlich 24 stündige Agarkulturen von Staphylococcus aureus. Eine Agarkultur wurde abgeschabt, das so gewonnene Material auf der inneren Wandfläche eines Reagensglases ganz fein verrieben und dann mit $20 \mathrm{~cm} 1.5$ prozent. Kochsalzlösung aufgeschwemmt („Staph.“). Die Lenkozyten gewann ich 
aus dem Peritonealexsudat eines Meerschweinchens, dem $21 / 2$ bis 3 Stunden vorher 7 bis $10^{\mathrm{com}}$ gewöhnlicher Bouillon eingespritzt worden waren. Das Peritonealexsudat warde mit einer Citratiösung (1.5 Prozent Natriumcitrat und 0.85 Prozent Chlornatrium) und mit einer geringen Menge Herzblut versetzt, mit mäßiger Geschwindigkeit zentrifugiert, dekantiert, mit physiologischer Lösung zweimal gewaschen, und das Sediment dann mit 1.5 prozentiger Kochsalzlösung auf ungefähr $1 / 4$ Volum des Exsudates aufgeschwemmt („Leuk."). Der Zusatz geringer Mengen von Blut ist sehr zweckmäBig. Wenn die Leukozyten allein aufgeschwemmt werden und wenn sie dann besonders mit einer eiweiBarmen Flüssigkeit wie $C$, oder mit Kochsalzlösung, gemischt werden, so geschieht es sehr leicht, daB sie bei der weiteren Behandlung (Färben, Waschen usw.) vom Objektträger abgeschwemmt werden. Der Zusatz von roten Blutkörperchen bewahrt uns nicht nur vor diesem unangenehmen Ereignisse, sondern erleichtert außerdem auch noch die nachherige mikroskopische Zählung, weil man in jedem Gesichtsfeld stets eine Anzahl von roten Blutzellen findet und dadurch bald das Mikroskop richtig einstellen kann.

Die Versuchsanordnung gestaltete sich in der Weise, dab in kleinen Röhrchen $0.1^{\mathrm{cem}}$ der Staphylokokkenemulsion, 0.1 com einer der Substanzen $\mathrm{A}, \mathrm{B}, \mathrm{C}, \mathrm{D}$ (oder $0 \cdot 2^{\mathrm{ccm}}$ von $\mathrm{C}+\mathrm{D} \overline{\mathrm{as}}$ ) und $0 \cdot 1^{\mathrm{ccm}}$ Leukozytenaufschwemmung gemischt wurde. Der Inhalt aller Röhrchen wurde mit physiologischer Kochsalzlösung zum gleichen Volumen, in der Regel auf $0.4^{\mathrm{cem}}$ aufgefüllt, gut gemischt, und die Röhrchen 20 Minuten lang in einen Brütschrank von $37^{\circ}$ gesetzt. Dann wurde ein Tropfen von jedem Gemisch mit einer Platinöse auf einem gut gereinigten Objektträger ausgestrichen, getrocknet, mit konzentrierter Sublimatlösung fixiert und mit verdünnter Löfflerscher Lösung gefärbt. Zur Berechnung des phagozytären Index wurden gewöhnlich 50 polynukleäre Leukozyten gezählt. Wenn die Zahl der von einzelnen Leukozyten aufgefressenen Bakterien nahezu gleich ist, wie es in meinen Versuchen bei attivem Normalserum der Fall war, so genügt schon die Zählung von 30 Leukozyten. Falls dagegen die Phagozytose ganz ungleichmäBig vor sich gegangen war, so zählte ich 100, zuweilen auch 200 oder noch mehr Leukozyten. Eine derartige unregelmäBige Phagozytose fand sich besonders dann, wenn die mit Dialysatssediment beladenen und zentrifugierten Kokken gebraucht wurden. Das Globulin haftet an den Kokken und macht dieselben so llebrig, daß sie sich bei der Zentrifugierung zu einem Konglomerat zusammenballen, von welchem eine gleichmäBige Aufschwemmung nur recht schwer wiederherzustellen ist.

In folgendem sollen die Resultate der opsonischen Versuche mit verschiedenen dialysierten Seris in Tabellenform wiedergegeben werden. 
Tabelle XII.

Opsonische Versuche mit 24 Stunden lang gegen Leitungswasser dialysiertem Meerschweinchenserum. (Vgl. Tabelle I.)

\begin{tabular}{|c|c|c|c|}
\hline $\begin{array}{c}\text { Nummer } \\
\text { des Röhrchens }\end{array}$ & $\begin{array}{c}\text { Gemisch von } \\
\mathrm{ccm}\end{array}$ & Phagozytärer Index & Relativer Index \\
\hline 1 & 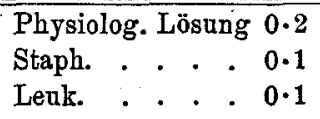 & $2 \cdot 74$ & 0.18 \\
\hline 2 & 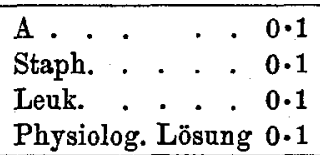 & $14 \cdot 47$ & $1 \cdot 00$ \\
\hline 3 & 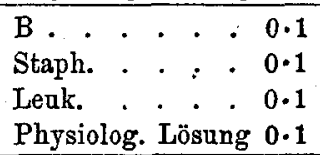 & $12 \cdot 36$ & 0.85 \\
\hline 4 & 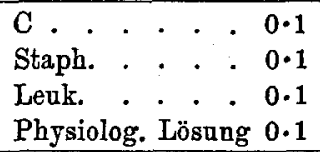 & $3 \cdot 59$ & 0.23 \\
\hline 5 & 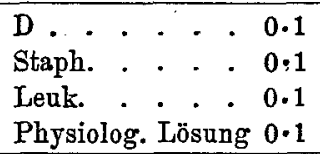 & $2 \cdot 35$ & $0 \cdot 16$ \\
\hline 6 & 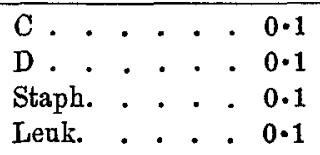 & 10.57 & 0.73 \\
\hline
\end{tabular}

Hier zeigt das Filtrat $\mathrm{C}$ einen etwas höheren Index als Kochsalzlösung, während das Sediment ungefähr den gleichen Index wie diese Kontrolle ergibt.

In den folgenden Tabellen wird der Inhalt des Röhrchens nicht mehr genan wiedergegeben, weil er stets ganz gleich wie in Tabelle XII war.

Tabelle XIII.

Opsonische Versuche mit 24 Stunden lang gegen Leitungswasser dialysiertem Serum. (Vgl. Tabelle II.)

\begin{tabular}{c||c|c|c}
\hline \hline & & Phagozytärer Index & Relativer Index \\
\hline \hline 1 & Physiolog. Lösung & 0.39 & 0.05 \\
2 & A & 7.49 & 1.00 \\
3 & B & 6.20 & 0.82 \\
4 & C & 1.56 & 0.21 \\
5 & D. & 0.45 & 0.06 \\
6 & C + D & 5.92 & 0.79
\end{tabular}


Obgleich bei diesen Versuchen der phagozytäre Index durch viel niedrigere Zahlen zum Ausdruck kommt als in Tabelle XII, steht doch der relative Index der beiden in ganz gleichem Verhältnis.

In einem 48 Stunden lang gegen Leitungswasser oder destilliertes Wasser dialysiertem Serum war die opsonische Kraft sowohl des Gesamtdialysats als auch dessen Komponenten sehr schwach oder fast ganz verschwunden, so dab ein Vergleich mit deren hämolytischer Kraft fast unmōglich war. Daher will ich hier gleich zur Beschreibung der Versuche mit Serum, welches gegen das optimale Wassergemisch dialysiert worden war, übergehen.

\section{Tabelle XIV.}

Opsonische Versuche mit 24 Stunden lang gegen das optimale Wassergemisch dialysiertem Serum. (Vgl. Tabelle VIII.)

\begin{tabular}{|c|c|c|c|}
\hline & & $\begin{array}{l}\text { Phagozyt. } \\
\text { Index }\end{array}$ & $\begin{array}{l}\text { Relativer } \\
\text { Index }\end{array}$ \\
\hline 1 & Physiolog Lösung & $0 \cdot 46$ & 0.03 \\
\hline 2 & $\mathbf{A}$ & $15 \cdot 02$ & $1 \cdot 00$ \\
\hline 3 & B & $12 \cdot 03$ & 0.80 \\
\hline 4 & $\mathrm{C}$ & $0 \cdot 54$ & 0.03 \\
\hline 5 & $\mathrm{D}$. & 0.50 & 0.03 \\
\hline 6 & $\mathrm{C}+\mathrm{D}$ & $9 \cdot 15$ & $0 \cdot 61$ \\
\hline 7 & $\begin{array}{c}0.1 \mathrm{ccm} C+0.1 \mathrm{~cm} \text { Staph. warde nach } 30^{\prime} \text { in } 37^{\circ} \\
\text { zentrifugiert, wieder aufgeschwemmt }+0.2 \mathrm{ccm} \text { physio- } \\
\text { logische Lösung }+0.1 \mathrm{~cm} \text { Leuk }\end{array}$ & 0.58 & $0 \cdot 04$ \\
\hline 8 & $\begin{array}{c}0.1 \mathrm{ccm} \mathrm{C}+0.1 \mathrm{com} \text { Staph. wurde nach } 30^{\prime} \text { in } 37^{\circ}, \\
\text { zentrifugiert, wieder anfgeschwemmt }+0.1 \mathrm{~cm} \text { physio- } \\
\text { logische Lösung }+0.1^{\mathrm{cem}} \mathrm{D}+0.1 \mathrm{ccm} \text { Lenk. }\end{array}$ & 0.67 & 0.04 \\
\hline 9 & $\begin{array}{c}0.1 \text { eem } \mathrm{D}+0.1^{\mathrm{cem}} \text { Staph. wurde nach } 30^{\prime} \text { in } 37^{\circ} \\
\text { zentrifugiert, wieder aufgeschwemmt }+0.2^{\mathrm{ccm}} \text { physio- } \\
\text { logische Lösung }+0.1 \mathrm{com} \text { Leuk. }\end{array}$ & 0.26 & 0.02 \\
\hline 10 & $\mid \begin{array}{c}0.1 \text { ecm } \mathrm{D}+0.1 \mathrm{ccm} \text { Staph. wurde nach } 30^{\prime} \text { in } 37^{\circ} \\
\text { zentrifugiert, wieder aufgeschwemmt }+0.1 \mathrm{ccm} \text { physio- } \\
\text { logische Lösung }+0.1 \mathrm{cem} C+0.1 \mathrm{cem} \text { Leuk. }\end{array}$ & $11 \cdot 04$ & $0 \cdot 70$ \\
\hline
\end{tabular}

Die Resultate der Versuche mit gegen 1/550 Normal-NaCl-Lösung dialysiertem Serum waren ungefähr dieselben wie die in Tabelle XIV wiedergegebenen. Wie wir aus diesen Versuchsresultaten entnehmen können, zerfällt das Opsonin des normalen Neersehweinchenserums durch die Dialyse ebenso wie das hämolytische Komplement in zwei an und für sich unwirksame Komponenten. Durch Wiederrereinigung dieser beiden Komponenten erhält man ungefähr eine ebenso starke opsonische Wirksamkeit wieder, wie sie das Gesamtdialysat besitzt. Auch bei den 
opsonischen Versuchen scheint das Filtrat die Rolle als Endstück, das Sediment die des Zwischenstückes zu spielen. Wenn wir aber die opsonische Wirksamkeit des Gesamtdialysats oder des Gemisches, Filtrat + Sediment, mit der des Originalserums vergleichen, so bemerken wir eine deutliche Verminderung des Opsonins durch die Dialyse. Der relative Index des Gesamtdialysats war meistens kleiner als 0.8 , zuweilen in anderen hier nicht angeführten Versuchen sogar nur gleich 0.6 oder noch geringer. Bei den hämolytischen Versuchen war dagegen die komplettierende Kraft des Gesamtdialysates ungefähr gleich stark wie die des Originalserums, wenn auch immerhin eine geringe Verminderung durch die Dialyse bemerkbar war. Soviel steht nach unseren hier wiedergegebenen Versuchen fest, daß das Opsonin oder ein Bestandteil desselben ebenso wie das hämolytische Komplement sich aus zwei Komponenten zusammensetzt, daß jedoch das opsonische Agens viel empfindlicher gegenüber den physikalisch-chemischen Einflüssen der Dialyse ist als der die Hämolyse auslösende Körper.

c) Thermolabität des Normalopsonins.

Normales Meerschweinchenserum wurde 30 Minuten lang auf $56^{\circ}$ erhitzt und auf seine opsonische Wirksamkeit untersucht. Einige Beispiele dieser Versuche zeigt die Tabelle $\mathrm{XV}$.

Tabelle XV.

\begin{tabular}{c||c|c|c}
\hline \hline \multirow{2}{*}{ Versuchs-Nr. } & \multicolumn{3}{|c}{ Der phagozytäre Index von } \\
& physiolog. Lösung & dem frischen Sernm & dem erhitzten Serum \\
\hline 1 & 0.63 & 4.57 & 0.48 \\
2 & 0.42 & 6.81 & 0.17 \\
3 & 0.58 & 5.63 & 0.14
\end{tabular}

Danach besitzt das erhitzte Serum allein keine opsonische Kraft mehr. Bemerkenswert ist dabei, daB der phagozytäre Index des erhitzten Serums oft geringer als der der physiologischen Lösung war. Derartig erhitztes Serum hatte natürlich keine hämolytisch komplettierende Kraft. Bezüglich der Resistenz gegen Hitze verhielten sich somit die hämolytische und die opsonische Substanz des Serums ganz gleich.

d) Absorptionsversuche durch Zusatz von Bakterienemulsionen zum Meerschweinchenserum.

Frisches Meerschweinchenserum wurde zunächst mit dem gleichen Volumen der dünnen Bakterienemulsion, wie sie bei den opsonischen Ver- 
suchen gebraucht wurde, versetzt, 30 Minuten lang bei $37^{\circ}$ gehalten, dann ganz klar zentrifugiert. So mit Bakterien behandeltes Serum wurde sowohl auf seine hämolytische als auch auf seine opsonische Kraft geprüft.

Tabelle XVI.

\begin{tabular}{|c|c|c|c|}
\hline \multicolumn{2}{|c|}{ Mengen in ccm } & \begin{tabular}{|c} 
A. \\
Auf die doppelte Menge \\
mit physiologischer Lösung \\
verdünntes frisehes Serum
\end{tabular} & $\begin{array}{c}\text { B. } \\
\text { Mit der gleichen Menge } \\
\text { Bakterienemulsion } \\
\text { behandeltes Serum }\end{array}$ \\
\hline $\begin{array}{c}\text { Hämolytisch } \\
\text { komplettierende } \\
\text { Kraft }\end{array}$ & $\begin{array}{l}0.2 \\
0.1 \\
0.08 \\
0 \cdot 04 \\
0 \cdot 02 \\
0 \cdot 01 \\
0 \cdot 004\end{array}$ & $\begin{array}{c}\text { komplett } \\
\text { " } \\
\text { fast komplett } \\
\text { stark } \\
\text { schwach } \\
\text { Spur }\end{array}$ & $\begin{array}{c}\text { komplett } \\
\text { fast komplett } \\
\text { stark } \\
\text { schwach } \\
\text { Spur } \\
\text { " }\end{array}$ \\
\hline $\begin{array}{l}\text { Phagozytärer } \\
\text { Index }\end{array}$ & 0.1 & $18 \cdot 73$ & 7.18 \\
\hline
\end{tabular}

Bei diesem Versuche wurden durch die Behandlung mit Bakterien beide Erscheinungen nur abgeschwächt gefunden. Es muB hierbei erwähnt werden, daB, als ich nach 30 Minuten langer Bebrūtung untersuchte, noch gar keine Hämolyse in der Reihe B bemerkbar war, während in cler Reihe A schon deutliche Hämolyse stattgefunden" hatte. Nach 1 stündigem Verweilen im Brütschrank war dagegen auch in B die ziemlich starke Hämolyse, wie die Tabelle sie verzeichnet, eingetreten. Diese Tatsache zwingt uns zu der Annahme, daB die Affinität des Komplements nicht einheitlich ist, indem durch eine 30 Minuten lange Behandlung mit Bakterien ein Teil des Komplements, nämlich der, welcher die stärkere Affinität hat, an die Bakterien gebunden wird, während der andere Teil von schwächerer Affinität im Serum zurückbleibt.

Es wurde nunmehr ein zweiter Versuch mit ganz dicker Emulsion durchgeführt. 10 Agarkulturen wurden in physiologischer Lösung aufgeschwemmt und dann zentrifugiert. Das derartig gewaschene Bakteriensediment wurde in $5 \mathrm{~cm}$ physiologischer Lösung aufgeschwemmt (,DickStaph."). Ein Teil dieser dicken Aufschwemmung wurde 20 fach verdünnt (,Dünn-Staph.“). Das einmalige Waschen der Bakterien ist deshalb zweckmäBig, weil durch diese Vorbehandlung die Bakterien von jeglichen interzellularen Substanzen befreit werden und bei der nachherigen Zentrifugierung sich leichter rom Serum abscheiden. Letzterer Umstand ist besonders für die unten näher zu beschreibenden Absorbierungsversuche in der Kälte sehr wichtig. 
Mit diesen beiden Anfschwemmungen wurde frisches Serum in der oben beschriebenen Weise behandelt.

\begin{tabular}{|c|c|c|c|c|}
\hline \multicolumn{2}{|c|}{ Menge in $\mathrm{ccm}$} & $\begin{array}{c}\text { A. } \\
\text { Mit physiolog. Lösung } \\
2 \text { fash verdünntes } \\
\text { frisches Serum }\end{array}$ & $\begin{array}{c}\text { B. } \\
\text { Mit gleicher Menge } \\
\text { „Dick-Staph.“ } \\
\text { behandeltes Serum }\end{array}$ & $\begin{array}{c}\text { C. } \\
\text { Mit gleicher Menge } \\
\text { „Dünn-Staph.“” } \\
\text { behandeltes Serum }\end{array}$ \\
\hline 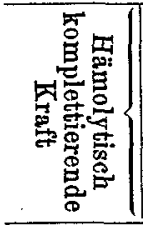 & \begin{tabular}{l|}
0.2 \\
0.1 \\
0.06 \\
0.02 \\
0.01 \\
0.006 \\
\end{tabular} & $\begin{array}{c}\text { komplett } \\
\text { " } \\
\text { fast komplett } \\
\text { stark } \\
\text { schwach } \\
\end{array}$ & $\begin{array}{c}\text { Spar } \\
\text { Spürchen } \\
- \\
- \\
- \\
- \\
\end{array}$ & $\begin{array}{c}\text { komplett } \\
\text { fast komplett } \\
\# \\
\text { stark } \\
\text { schwach } \\
\text { Spar }\end{array}$ \\
\hline $\begin{array}{l}\text { hagozyt. } \\
\text { Index }\end{array}$ & 0.1 & 13.08 & $2 \cdot 58$ & $6 \cdot 94$ \\
\hline
\end{tabular}

Die Kontrolle mit physiologischer Lösung zeigte einen phagozytären Index von 1.26.

Durch die Behandlung mit Dick-Staph. wurde also das Serum seiner hämolytischen und op sonischen Wirksamkeit fast gänzlich beraubt, während durch Dünn-Staph. diese beiden Fähigkeiten nur ungefähr gleichmäßig abgeschwächt wurden. Die gleichen Versuche wurden auch noch mit Tuberkelbazillen mit den nämlichen Resultaten ausgeführt, worüber weiter unten bei der Erörterung der Spezifizitätsfrage noch die Rede sein soll.

Aus den Resultaten der bisher angeführten Dialysierangs-, Erhitzungsund Absorptionsrersuche können wir ersehen, daB die opsonische Wirkung des normalen Meerschweinchenserums in sehr naher Beziehung zu der hämolytisch komplettierenden Kraft desselben steht, denn sie zeigen völlige Analogie.

\section{Konstitution des Opsonins.}

Wright und Douglas (1) haben ein frisches Serum einerseits mit erhitztem Serum, andererseits mit physiologischer Lösung verdünnt und in beiden Verdünnungen fast die gleiche opsonische Kraft gefunden. Sie konnten also das inaktive Serum nicht reaktivieren. Dagegen gelang dies Cowie und Chapin (7) dadurch, daB sie einer bestimmten Menge erhitzten Serums die gleiche Menge von 15 bis 20 fach verdünntem frischem Serum zusetzten. Sie haben fast ausschlieBlich mit Menschenserum gearbeitet und nur einmal Meerschweinchenserum als Komplement gebraucht. In diesem Fall war die Reaktivierung nicht so vollkommen, wie bei Menschenserum (vgl. ihr Experiment 3). Es scheint daher das Meerschweinchenserum weniger Komplement als Menschenserum gehabt zu haben. 
Einige Versuche mit einem durch physiologische Lösung verdünnten, frischen Meerschweinchenserum ergaben mir folgenden phagozytären Index (Tabelle XVIII).

Tabelle XVIII.

\begin{tabular}{|c|c|c|c|c|c|}
\hline \multirow{2}{*}{ Versuchs-Nr. } & \multicolumn{2}{|c|}{ Kontrolle mit $\left.\right|_{\text {Unverdünntes }}$} & \multicolumn{3}{|c|}{ Mit Kochsalzlösung verdünntes Serum } \\
\hline & $\begin{array}{l}\text { Lösang } \\
\text { Lös. }\end{array}$ & Serum & $10 \times$ & $20 x$ & $30 \times$ \\
\hline 1 & 0.43 & 6.81 & 1.85 & $1 \cdot 10$ & 0.53 \\
\hline 2 & 0.63 & 8.57 & $2 \cdot 08$ & $1 \cdot 50$ & 0.46 \\
\hline 3 & 0.58 & $20 \cdot 05$ & $7 \cdot 80$ & $3 \cdot 50$ & $1 \cdot 87$ \\
\hline 4 & 0.28 & $15 \cdot 87$ & $2 \cdot 75$ & $1 \cdot 52$ & 0.87 \\
\hline
\end{tabular}

Die hier wiedergegebenen Resultate veranlaßten mich bei den späteren Versuchen ein 20 fach verdünntes, frisches Serum als Komplement zur Reaktivierung des erhitzten Serums zu benutzen. Dieselben wurden zunächst in der Weise ausgeführt, daß $0.1^{\mathrm{cem}}$ des auf $56^{\circ}$ erhitzten Serums und die gleiche Menge des verdünnten, frischen Serums einfach gemischt und je $0.1^{\mathrm{ccm}}$ von Staph. und Leuk. zugesetzt wurde. Die Resultate solcher Versuche waren, wie aus der folgenden Tabelle XIX ersichtlich, sehr abweichend voneinander. Diese UnregelmäBigkeiten mögen wohl dadurch bedingt sein, daB in den Gemischen relativ wenig Komplement gegenüber großen Ambozeptormengen sich vorfindet, und demzufolge bald ein gröBerer, bald ein kleinerer Teil des Komplements durch den freien Ambozeptor abgelenkt wird.

Tabelle XIX.

\begin{tabular}{|c|c|c|c|c|c|}
\hline Versuchs-Nr. & $\begin{array}{l}\text { Kontrolle } \\
\text { mit } \\
\text { physiolog. } \\
\text { Lösung }\end{array}$ & $\begin{array}{l}\text { Frisches } \\
\text { Serum } \\
0 \cdot 1 \text { ccm }\end{array}$ & $\begin{array}{l}20 \text { fach } \\
\text { verdünntes } \\
\text { Serum } \\
0 \cdot 1_{\text {com }}\end{array}$ & $\begin{array}{l}\text { Auf } 56^{\circ} \\
\text { erhitztes } \\
\text { Serum } \\
0 \cdot 1\end{array}$ & $\begin{array}{l}\text { Auf } 56^{\circ} \text { erhitztes } \\
\text { Serum }+20 \text { fach } \\
\text { verdünntes } \\
\text { Serum } \overline{a a} 0.1\end{array}$ \\
\hline 1 & 0.43 & $6 \cdot 81$ & $1 \cdot 10$ & 0.17 & 0.62 \\
\hline 2 & $0 \cdot 65$ & $7 \cdot 37$ & 0.97 & 0.48 & 0.85 \\
\hline 3 & $1 \cdot 13$ & $13 \cdot 92$ & $2 \cdot 79$ & 0.67 & $3 \cdot 87$ \\
\hline 4 & 0.58 & $5 \cdot 62$ & 0.62 & 0.14 & $0 \cdot 57$ \\
\hline 5 & 0.24 & $12 \cdot 46$ & 0.62 & 0.57 & $5 \cdot 87$ \\
\hline
\end{tabular}

Nach dieser Uberlegung modifizierte ich die Versuchsanordnung in der Weise, daß die Bakterienemulsion zaerst mit der gleichen Menge erhitzten Serums gemischt 30 Minuten lang bei $37^{\circ} \mathrm{im}$ Brütschrank aufbewahrt, dann zentrifugiert wurde. Diese mit erhitztem Serum beladenen, aber von den freien, überflüssigen Ambozeptoren befreiten Bakterien $\left(,, 56^{\circ}\right.$ Serum Staph.") wurden wieder auf das Ausgangsvolumen aufgeschwemmt, dann mit der gleichen Menge des verdünnten, frischen Serums versetzt. Diese Versuche ergaben etwas bessere aber noch nicht ausschlaggebende Resultate. (Vgl. Tabelle XX und XXI 9.) 
e) Absorptionsversuche bei niedrigen Temperaturen.

Bulloch und Atrin (3) fanden das bei $0^{\circ}$ mit Bakterien vorbehandelte Serum als opsonisch ganz unwirksam (Experiment 2). Dagegen konnten Cowie und Chapin (14) zeigen, daB ein bei $0^{\circ}$ mit Bakterien vorbehandeltes Serum zwar an und für sich auf gewöhnliche Bakterien wirkungslos war, daß es aber gegen Bakterien, welche mit. auf $56^{\circ}$ erhitztem Serum beladen waren und gegen mit frischem Serum bei $0^{\circ}$ beladene Bakterien opsonisch komplettierend wirkte. Durch dieses Resultat wurde ihre Annahme, daB das Opsonin aus zwei Komponenten, Ambozeptor und Komplement, bestehe, sicher unterstützt.

Zur Nachprüfung der Cowie und Chapinschen Versuche wurden folgende Materialien hergestellt:

1. Fr. Serum $=2$ fach mit physiologischer Lösung verdünntes frisches Meerschweinchenserum.

2. $0^{\circ}$ Staph.-Serum $=$ Frisches Serum und die obenbeschriebene Bakterienaufschwemmung „Dick-Staph." wurden in einer Kältemischung bis auf $-2^{0}$ abgekühlt. Dann wurden gleiche Teile dieser beiden Substanzen mit vorher abgekühlten Pipetten in einem ebenfalls gekühlten Glasröhrchen zusammengebracht. Dies Gemisch wurde 1 Stunde lang in der Kälte unter oftmaliger Schüttelung aufbewahrt, dann schnell zentrifugiert. Da mir ein Kühlraum nicht zur Verfügung stand, habe ich die Zentrifugierung in folgender Weise durchgeführt. In einen Zentrifugeneinsatz wurde eine Kältemischung von ungefähr $-10^{\circ}$ gebracht und in diese ein mit einer Kältemischung von $-2^{0}$ gefülltes Glaszylinderchen eingetaucht. In letzterer Kältemischung fand das die Serum-Bakterienmischung enthaltende Glasröhrchen seinen Platz. Die Zentrifugierung soll 15 Minuten lang bei voller Geschwindigkeit stattfinden. Nach 15 Minuten muB die Temperatur der inneren Kältemischung noch weniger als $+5^{0}$ betragen, da sonst das gewonnene Serum nicht mehr gebraucht werden kann.

3. $0^{\circ}$ Serum-Staph. $=$ die gewöhnliche Staphylokokkenemulsion und frisches Serum wurden zu gleichen Teilen in der Kälte gemischt, und nach 1 Stunde zentrifugiert. Die sedimentierten Bakterien wurden mit physiologischer Lösung von $0^{0}$ gewaschen, nochmals zentrifugiert, und dann auf das Ausgangsvolumen aufgeschwemmt.

4. $56^{\circ}$ Serum-Staph. $=$ die gewöhnliche Staphylokokkenemulsion wurde mit gleicher Menge des auf $56^{\circ}$. erhitzten Serums versetzt, 30 Minuten lang bei $37^{\circ}$ im Brütschrank gehalten, dann zentrifugiert und wieder aufgeschwemmt. 
5. $1 / 20$ Fr. Serum $=20$ fach mit physiologischer Lösung verdünntes frisches Serum.

6. Gewöhnl. Staph. = die gewöhnliche dünne Staphylokokkenemulsion.

Aus diesen Materialen wurden verschiedene Mischungen hergestellt und auf ihre opsonische Kraft untersucht. Zum Vergleich wurde das "0 $0^{0}$ Staph.-Serum" einem hämolytischen Versuche unterzogen. Die Resultate sind in folgenden zwei Tabellen ersichtlich gemacht.

\section{Tabelle XX.}

1. Opsonische Versuche.

\begin{tabular}{|c|c|c|}
\hline Nr. & Verschiedene $G$ emische & $\begin{array}{l}\text { Phagozyt. } \\
\text { Index }\end{array}$ \\
\hline 1 & $0.2^{\mathrm{ccm}}$ phyosiol. Lösung $+0.1^{\mathrm{com}}$ gewöhnl. Staph. $+0.1^{\mathrm{cem}}$ Leuk. & $1 \cdot 13$ \\
\hline 2 & $\begin{array}{c}0.1^{\mathrm{cmm}} \text { Fr. Serum }+0.1^{\mathrm{ccm}} \text { physiol. Lösung }+0.1^{\mathrm{ccm}} \text { gewöhnl. Staph. } \\
+0.1 \mathrm{cem} \text { Leuk. }\end{array}$ & $7 \cdot 14$ \\
\hline $\mathbf{3}$ & + desgl. $\quad+$ desgl. $\quad+$ desgl. & $1 \cdot 33$ \\
\hline 4 & $0.1^{\mathrm{cm}} 0^{0}$ Staph.-Serum + desgl. & $1 \cdot 17$ \\
\hline 5 & $0.1 \mathrm{~cm} 56^{\circ}$ Serum-Staph. $+0.2^{\mathrm{ccm}}$ physiol. Isösung $+0.1^{\mathrm{cm}}$ Leuk. & $0 \cdot 84$ \\
\hline 6 & 0.1 cem 00 Serum-Staph. $+\quad "$ & $2 \cdot 04$ \\
\hline 7 & 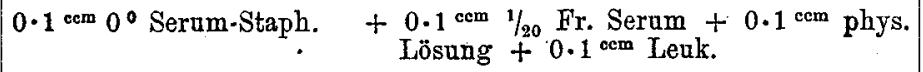 & $5 \cdot 95$ \\
\hline 8 & 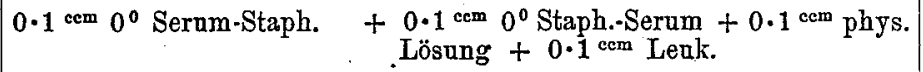 & $6 \cdot 77$ \\
\hline 9 & $\begin{aligned} 0.1^{\mathrm{ccm}} 56^{\circ} \text { Serum-Staph. }+ & \begin{array}{l}0.1^{\mathrm{ccm}} 1 / 20 \mathrm{Fr} . \text { Serum } \\
\text { Lösung }+0.1^{\mathrm{com}} \text { Leuk. }\end{array}+0.1^{\mathrm{ccm}} \text { phys. }\end{aligned}$ & $3 \cdot 43$ \\
\hline 10 & $\begin{aligned} 0.1^{\mathrm{cm}} 56^{\circ} \text { Serum-Staph. }+ & 0.1^{\mathrm{cem}} 0^{0} \text { Staph.-Serum }+0.1^{\mathrm{cem}} \text { phys. } \\
& \text { Lösung }+0.1 \mathrm{cem} \text { Leuk. }\end{aligned}$ & 6.04 \\
\hline
\end{tabular}

\section{Hämolytische Versuche.}

\begin{tabular}{c|c|c}
\hline Menge des Serums in cem & Frisches Serum & $0^{\circ}$ Staph.-Serum \\
\hline \hline 0.1 & komplett & komplett \\
0.04 & fast kompl. & stark \\
0.02 & stark & $"$ \\
0.01 & schwach & schwach \\
0.004 & & Spur
\end{tabular}


Tabelle XXI.

1. Opsonische Versuche.

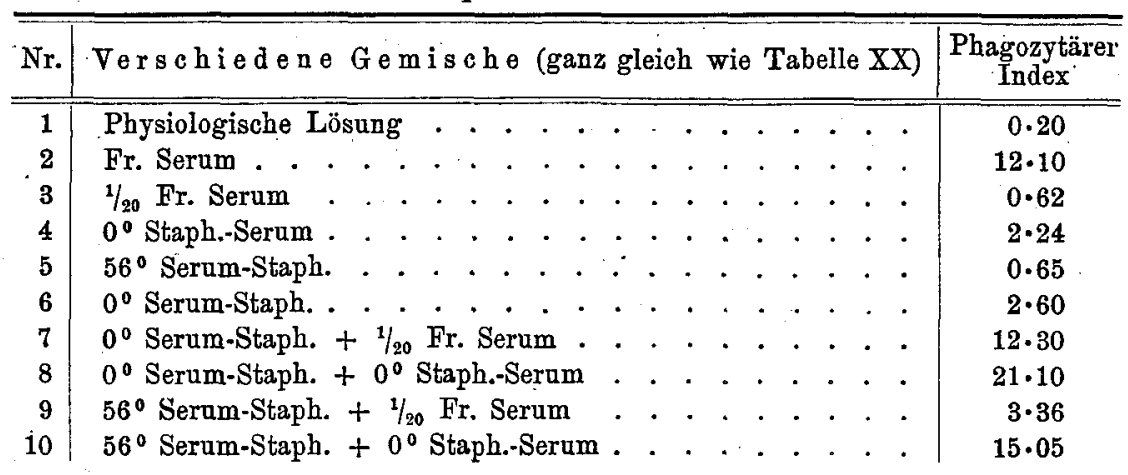

2. Himolytische Versuche.

\begin{tabular}{c|c|c}
\hline \hline Menge des Serums in ccm & Frisches Serum & $0^{\circ}$ Staph.-Serum \\
\hline \hline 0.1 & komplett & fast komplett \\
0.04 & fast komplett & stark \\
0.02 & stark & schwach \\
0.01 & schwach & "” \\
0.004 & , & Spur
\end{tabular}

Beide Versuche gaben übereinstimmende Resultate, welche die Cowieund Chapinsche Angabe vollkommen bestätigen. Es wird nämlich in der Kälte nur eine Komponente des Opsonins an Bakterien gebunden, während eine andere im Serum zurückbleibt. Jede dieser beiden Komponenten ist an und für sich wirkungslos, aber bei ihrer Vereinigung wird die opsonische Kraft des Serums vollkommen wiederhergestellt.

In dem in der Kälte mit Bakterien behandelten Serum ( $0^{\circ} \mathrm{Staph} .-$ Serum) bleibt das hämolytische Komplement fast unversehrt. „,0 Staph.Serum" wirkt nicht nur auf die, $0^{\circ}$ Serum-Staph.", sondern auch auf „560 0 Serum-Staph." opsonisch komplettierend. Meine Versuchsresultate weichen von den Cowie- und Chapinschen Resultaten nur in soweit ab, als die komplettierende Kraft des 20 fach verdünnten, frischen Serums auf ,56 ${ }^{\circ}$ Serum-Staph." und selbst auch auf, $0^{\circ}$ Serum-Staph." unvollständig war, während sie bei ihren Versuchen voll erhalten war.

Der gleiche Versuch wurde auch mit Tuberkelbazillen angestellt. Über die Versuchsanordnung und die Bezeichnung der Materialien erübrigen sich nähere Angaben, da mit der einzigen Ausnahme, daB statt der Staphylokokken Tuberkelbazillen in Anwendung gelangten, alles analog wie bei den vorhergehenden Versuchen gehandhabt wurde. 
Tabelle XXII.

1. Opsoniseher Versuch.

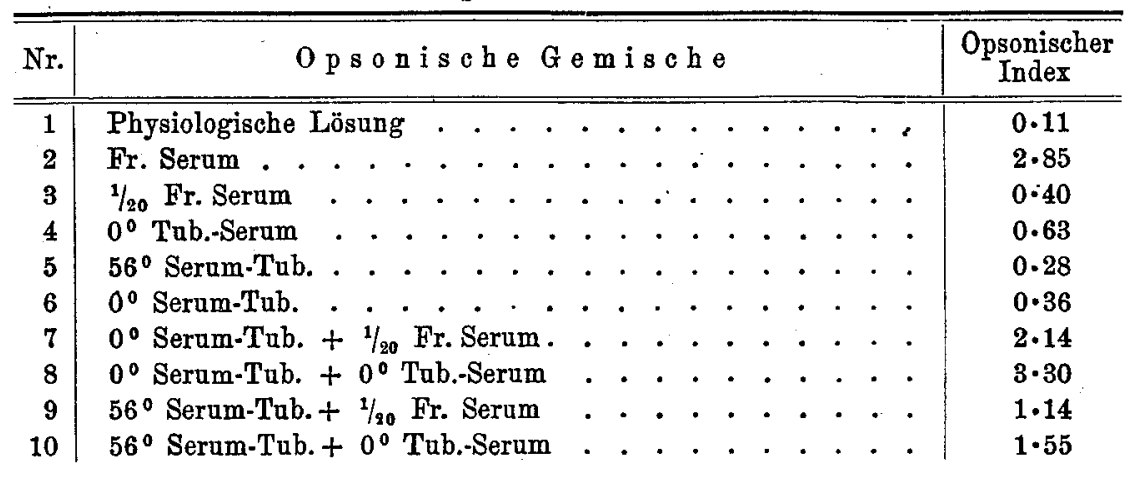

2. Hümolytischer Versuch.

\begin{tabular}{c|c|c}
\hline Menge des Serums in ccm & Frisches Serum & $0^{\circ}$ Tub.-Serum \\
\hline 0.1 & komplett & fast komplett \\
0.04 & fast komplett & stark \\
0.02 & stark & " \\
0.01 & schwach & schwach \\
0.004 & schwach & Spur
\end{tabular}

Durch diese Versuche ist bewiesen, daB die opsonische Fähigkeit des Normalserums durch Zusammenwirken zweier Komponenten, im Sinne Ehrlichs von Ambozeptor und Komplement, zustande kommt.

\section{Spezifizität des Normalopsonins.}

Die Annahme, daB die Bakteriotropine oder Immunopsonine von Kranken oder Immuntieren spezifisch nur gegen die betreffenden Krankheitskeime einwirken, scheint von den meisten Autoren akzeptiert zu werden. Über die Spezifizität des Normalopsonins herrseht jedoch noch Meinungsverschiedenheit. Bulloch und Western (15) behandelten ein Serum mit Staphylokokken. Das so behandelte Serum wirkte nicht mehr gegen Staphylokokken, jedoch noch gegen Pyocyaneusbazillen. In derselben Weise fanden sie eine Verschiedenheit der Opsonine gegen Staphylokokken und Tuberkelbazillen. Auch Rosenow (16) konnte im Menschenserum spezifische Opsonine gegen Pneumokokken, Streptokokken, Staphylokokken und Tuberkelbazillen nachweisen. Bächer (4) konnte das Opsonin durch Behandlung mit Bakterien, aber auch durch Versetzen mit anderen Fremdkörperchen aus einem Serum absorbieren, doch will er daraus noch nicht 
auf die Nichtspezifizität des Opsonins schließen. Muir und Martin (5) wollen nach ihren oben zitierten Versuchsergebnissen das Opsonin mit dem hämolytischen und bakteriolytischen Komplement identifiziert wissen. Danach müBte das Opsonin einheitlich und nicht spezifisch sein. Axamit und Tsuda (17) absorbierten das Opsonin aus einem Serum durch Staphylokokken, Dysenteriebazillen oder Subtilisbazillen. Derartig vorbehandeltes Serum war nicht nur gegen die Bakterienart, welche zur Vorbehandlung gedient hatte, sondern auch gegen alle anderen Bakterien wirkungslos. Eine Spezifizität des Opsonins schien ihnen danach ausgeschlossen.

Wenn man, wie es die meisten Autoren gemacht haben, das Serum bei : Brutwärme oder Zimmertemperatur mit einer Bakterienart behandelt, so ist von Anfang an zu erwarten, daß das Komplement sich an die Bakterien bindet, und das Serum durch Mangel an Komplement unwirksam gegenüber allen anderen Bakterien bzw. irgend einem Rezeptor wird. Dadurch kann eine Nichtspezifizität vorgetäuscht werden.

Schon in Tabelle XVII war ersichtlich gemacht, daß ein bei $37^{\circ}$ mit Staphylokokken behandeltes. Serum nicht nur gegen diese Bakterien opsonisch unwirksam, sondern auch hämolytisch wirkungslos geworden war. Als ich die opsonische Wirkung dieses Serums auf Tuberkelbazillen untersuchte, gelangte ich zu einem Resultate, welches mit den Axamitund Tsudaschen gleichbedeutend war.

Tabelle XXIII. (Vgl. Tabelle XVII.)

\begin{tabular}{l||c|c|c|c}
\hline & $\begin{array}{c}\text { Kontrolle } \\
\text { mit } \\
\text { physiolog. } \\
\text { Lösung }\end{array}$ & $\begin{array}{c}\text { Kontrolle } \\
\text { mit 2 fach } \\
\text { verdünntem, } \\
\text { frischem } \\
\text { Serum }\end{array}$ & $\begin{array}{c}\text { Bei 370 mit } \\
\text { gleicher Menge } \\
\text { "Dick-Staph.“ } \\
\text { behandeltes } \\
\text { Serum }\end{array}$ & $\begin{array}{c}\text { Bei 370 mit } \\
\text { gleicher Menge } \\
\text { "Dünn-Staph.“ } \\
\text { behandeltes } \\
\text { Sernm }\end{array}$ \\
\hline $\begin{array}{c}\text { Opsonischer Index } \\
\text { gegen Staphylokokken } \\
\text { Opsonischer Index }\end{array}$ & 1.26 & $13 \cdot 08$ & 2.58 & 6.94 \\
gegen Tuberkelbazillen & 0.10 & $2 \cdot 65$ & 0.28 & 1.42
\end{tabular}

Danach hat also das mit "Dick.-Staph." behandelte Serum seine opsonische Kraft gegen Staphylokokken, sowie gegen Tuberkelbazillen, sowie auch .seine hämolytische Wirksamkeit (vgl. Tabelle XVII) fast gänzlich verloren, und in einem mit „Dünn.-Staph.“ behandelten Serum waren diese drei Wirkungen ungefähr gleichmäßig stark vermindert. Dieses Resultat wurde durch eine Wiederholung des Versuchs vollständig bestätigt.

Ebenso ergab auch ein zu einem analogen Versuch verwendetes, mit Tuberkelbazillen bei $37^{\circ}$ vorbehandeltes Serum ein ganz gleiches Resultat. 
Tabelle XXIV.

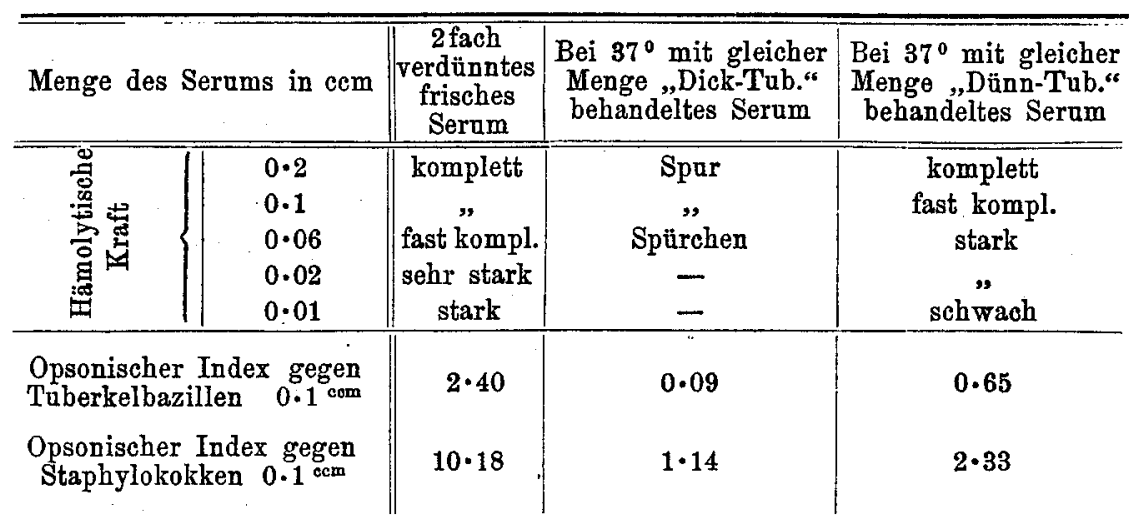

Damit sind die Axamit- und Tsudaschen Versuchsresultate hinsichtlich der Tatsachen bestätigt, doch sehe ich mich auf Grund weiterer, gleich näher zu beschreibender Versuche zu einer abweichenden theoretischen Auffassung gezwungen.

Als ich nämlich diese Versuche mit den in der Kälte mit Bakterienemulsion behandelten Seris wiederholte, kam ich zu einem ganz anderen Resultat.

Tabelle XXV. (Vgl. Tabelle XXI.)

\begin{tabular}{|c|c|c|c|}
\hline & Fr. Serum & $0^{0}$ Staph.-Serum & Physiolog. Lösung \\
\hline $\begin{array}{l}\text { Opsonischer Index } \\
\text { gegen Staphylokokken }\end{array}$ & $12 \cdot 10$ & $2 \cdot 24$ & $0 \cdot 20$ \\
\hline $\begin{array}{l}\text { Opsonischer Index } \\
\text { gegen Tuberkelbazillen }\end{array}$ & $2 \cdot 04$ & $1 \cdot 98$ & $0 \cdot 03$ \\
\hline
\end{tabular}

Tabelle XXVI. (Vgl. Tabelle XXII.)

\begin{tabular}{|c|c|c|c|}
\hline & Fr. Serum & $0^{\circ}$ Tub.-Serum & Physiolog. Lösung \\
\hline $\begin{array}{l}\text { Opsonischer Index } \\
\text { gegen Tuberkelbazillen }\end{array}$ & 2.85 & 0.63 & $0 \cdot 11$ \\
\hline $\begin{array}{l}\text { Opsonischer Index } \\
\text { gegen Staphylokokken }\end{array}$ & $14 \cdot 05$ & $13 \cdot 87$ & 0.20 \\
\hline
\end{tabular}

Wenn wir also ein Serum in der Kälte mit einer Bakterienaufschwemmung behandeln, so verbindet sich mit den Bakterien nur der für diese Bakterienart passende opsonische Ambozeptor, während das hämolytische sowie das opsonische Komplement und auch die für andere Bakterienarten passenden Ambozeptoren im Serum zurückbleiben.

Danach ist es also nunmehr klar, daß der Ambozeptor des normalen Opsonins spezifischer Natur ist. 
Gegen die Einheitlichkeit des Komplements scheint nur der Umstand zu sprechen, daß bei der Dialyse das hämolytische Komplement keine erhebliche Einbuße erlitt, während die opsonische Kraft desselben Serums dabei stark vermindert wurde. Diese Tatsache allein berechtigt aber noch nicht zu der Annahme, daB die hämolytischen und opsonischen Komplemente verschieden seien, weil die Möglichkeit besteht, daB ein und dieselbe Substanz zwei verschiedene Wirkungen hat, von denen die eine energischer ist und demzufolge durch äußere Einflüsse weniger geschädigt wird als die andere.

\section{Sehluß.}

1. Das normale Meerschweinchenserum zerfällt durch die Dialyse gegen Wasser ron gewisser Salzkonzentration in zwei Komponenten. Jede dieser Komponenten ist an und für sich hämolytisch sowohl wie opsonisch unwirksam. Durch Vereinigung dieser Komponenten werden aber die beiden Fähigkeiten des Serums wiederhergestellt. Bei der Hämolyse und auch bei der Phagozytose wirkt die eine Komponente nach Brandscher Benennung als Zwischenstück, die andere als Endstück.

2. Durch Erhitzung auf $56^{\circ}$ verliert das Normalserum seine hämolytisch komplettierende Kraft und auch seine opsonische Wirksamkeit.

3. Das bei $37^{\circ}$ mit dichter Bakterienemulsion behandelte Serum besitzt weder opsonische noch hämoly tische Wirksamkeit.

4. Das normale Opsonin hat also sehr nahe Beziehungen zu dem hämolytischen Komplement.

5. Durch die Behandlung mit Bakterien in der Kälte wird das normale Serum in zwei Komponenten geteilt, von denen die eine sich mit den Bakterien verbindet, während die andere im Serum bleibt. So behandeltes Serum wirkt als hämolytisches Komplement ganz wie das nicht behandelte frische Serum, als Opsonin aber nicht mehr gegen dieselben Bakterien, mit welchen es vorbehandelt wurde.

6. Die in der Kälte mit frischem Serum beladenen Bakterien sind noch nicht reif für die Phagozytose, werden aber unter Einwirkung eines in der Kälte mit Bakterien vorbehandelten, für sich allein unwirksamen Serums von den Leukozyten aufgenommen. 
7. Ein normales Opsonin besteht daher aus zwei Bestandteilen, d. h. Ambozeptor und Komplement.

8. Das in der Kälte mit einer Bakterienaufsehwemmung behandelte Serum hat keine opsonische Kraft gegen dieselben Bakterien, mit welchen das Serum vorbehandelt wurde, wirkt aberauf andere Bakterienarten ebenso vollkommen opsonisierend wie das frische Serum. Die in der Kälte von den Bakterien absorbierte Substanz, nämlich der Ambozeptor des Opsonins ist also spezifisch für die einzelnen Bakterienarten.

An dieser Stelle möchte ich nicht versäumen, Hrn. Geh. Med.-Rat Prof. Dr. A. Wassermann für die mannigfache Anregung und Förderung, die er der vorliegenden Arbeit hat zuteil werden lassen, sowie Hrn. Dr. Lockemann für seine Unterstützung bei den Wässeranalysen meinen wärmsten Dank auszusprechen.

Anmerkang bei der Korrektur: Während der Drucklegung dieser Arbeit sind noch zwei Veröffentlichungen von Sleewijk (18) und Meyer (19) erschienen. Die beiden Autoren sind zu denselben SchluBfolgerungen bezüglich der Konstitution des Opsonins gelangt, wie ich. 


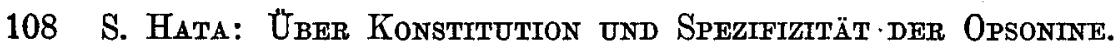

\section{Literatur.}

1. Wright and Douglas, Proceedings of Royal Society. Vol. LXXII. p.357.

2. Sauerbeck, Lubarsch-Ostertag's Ergebnisse der allgem. Pathologie. 1906. Abt. I. S. 690 .

3. Bulloch and Atkin, Proceedings of Royal Society. Vol. LXXIV. p. 379.

4. Bächer, Diese Zeitschrift. Bd. LVI.

5. Muir and Martin, British med. Journal. 1906. II. p. 1783.

6. Dean, Proceedings of Royal Society. Vol. LXXIV. Serie B. p. 506.

7. Cowie and Chapin, Journal of medical research. Vol. XVII. p.57.

8. Hektoen and Rüdiger, Journal of infectious diseases. 1905. p. 128 und 1906. p. 434.

9. Neumann, Centralblatt für Bakteriologie. Abt. I. Orig. Bd. XIIV. S. 46.

10. Ferrata, Berliner klin. Wochenschrift. 1907. Nr. 13.

11. Brand, Ebenda. 1907. Nr.34.

12. Hecker, Arbeiten aus dem Königl. Institut für experimentelle Therapie $z u$ Frankfurt a/M. 1907. Hft. 3.

13. Ne ufeld, Arbeiten aus dem Kraiserl. Gesundheitsamte. Bd. XXVIII. S. 212.

14. Cowie and Chapin, Journal of medical research. Vol. XVII. p. 95 a. 213.

15. Bulloch and Western. Zitiert nach Sanerbeck (Nr. 2).

16. Rosenow, Transact. of the Chicago pathological Society. Bd. VII. Nr. 2. Ref. in Deutsche med. Wochenschrift: 1908. Nr. 12. S. 522.

17. Axamit und Tsuda, Wiener klin. Wochenschrift. 1907. Nr. 35 .

18. Sleewijk, Centralblatt für Bateteriologie. Abt. I. Orig. Bd. XLVI. S. 513.

19. Meyer, Berliner klin. Wochenschrift. 1908. Nr. 20. S. 951. 